\title{
AsSESSMENTS UNDER tHe TAX AdMINISTRATION BILL
}

\author{
Lynette Olivier * \\ University of Johannesburg \\ lolivier@uj.ac.za
}

April 2011

Keywords

Assessments, Tax Administration Bill, jeopardy assessments, withdrawal of assessments, Prescription

* Prof Lynette Olivier is professor in the Department of Accountancy at the University of Johannesburg, South Africa. 


\section{INTRODUCTION}

The Tax Administration Bill (TAB) that will be tabled in parliament during this year will no doubt have a significant impact on the administration of all taxes. The drafting of the TAB was announced in the 2005 Budget Review as a project "to incorporate into one piece of legislation certain generic administrative provisions, which are currently duplicated in the different tax Acts". The scope of the project has since been extended so that it can now be seen as a preliminary step to the re-write of the Income Tax Act, 1962, since the administrative part of the Act comprises about $25 \%$ of the Act.

The aim of the $T A B$ is to set a general standard for the administration of all taxes administered by the South African Revenue Service (SARS) with the aim to create a balance between rights and obligations of taxpayers and the powers of SARS. As the TAB amends some of the existing rules, retains others and in other instances introduces completely new rules, every tax practitioner has to familiarise him or herself with $T A B$ as soon as possible.

One of the areas in which significant new rules was introduced is that of assessments. The aim of this article is to highlight the new rules applicable to assessments.

\section{DEFINITION OF AN ASSESSMENT}

It may be argued that an assessment forms the cornerstone of any action taken by SARS.

Currently, the term 'assessment' is broadly defined in s 1 of the Income Tax Act 59 of 1962 (the Act) as the written communication by SARS of a person's liability for tax. From the definition it is clear that three requirements exist for a valid assessment. First, the assessment must be in writing (Irvin \& Johnson (SA) Ltd v CIR 14 SATC 24, quoted with approval in Stroud v Riley Co v CIR 36 SATC 143). The second requirement is that it must contain the determination of an amount. In Holden's Estate v CIR 1960 (3) SA 497 (A) it was held that a determination of liability will only constitute an assessment if it SARS applied its mind. In other words, where it is objectively clear that an amount indicated as a taxpayer's liability is a mere thumb suck amount the document is not an assessment and SARS in not allowed to take any collection steps in regard to such amount. Thirdly, the determination must be communicated to the taxpayer (Singh v CSARS 65 SATC 203). Currently section 106 of the Act provides for several methods of communication, including transmission by electronic means to the taxpayer's last known. Although the proposed definition of the term 'assessment' in the TAB does not provide for notice to a taxpayer, clause 98 of the TAB provides that SARS has to give notice of an assessment to a taxpayer. Unlike the current s 106 of the Act (see discussion above) this clause does not provide for communication via electronic means. In addition, s 106 of the Act will be repealed.

Although the proposed definition of the term 'assessment' in the TAB does not provide for notice to a taxpayer, clause 96 of the TAB provides that SARS has to give notice of an assessment to a taxpayer. However, the clause does not indicate the way by which the type of notice, for example, b ordinary post, registered mail or by electronic means, should be given. It is submitted that this is an important shortcoming in the TAB.

The onus to proof that an assessment was not delivered rests on the taxpayer ( 822 and unreported decision of the Natal Tax Court delivered on 22 October 2001). Where the 
requirements for a valid assessment are not met, it is as if the assessment does not exist (CIR V Butcher Brothers (Pty) Ltd 1945 AD 302 at 322 and ITC 154554 SATC 464 at 469).

Although the proposed definition of the term 'assessment' in the TAB does not provide for notice to a taxpayer, clause 98 of the TAB provides that SARS has to give notice of an assessment to a taxpayer. Unlike the current $\mathrm{s} 106$ of the Act (see discussion above) this clause does not provide for communication via electronic means. In addition, s 106 of the Act will be repealed.

Although the proposed definition of the term 'assessment' in the TAB does not provide for notice to a taxpayer, clause 96 of the TAB provides that SARS has to give notice of an assessment to a taxpayer. However, the clause does not indicate the way by which the type of notice, for example, b ordinary post, registered mail or by electronic means, should be given. It is submitted that this is an important shortcoming in the TAB.

The definition in the Act of the term 'assessment' will be repealed and replaced with a new definition in the TAB. The definition in TAB currently read:

"means the determination of the amount of tax liability, by way of self-assessment by the taxpayer or assessment by the South African Revenue Service, and includes any decision which is subject to objection and appeal."

From this definition it is clear that it is clear that an assessment no longer has to be communicated to a taxpayer for it to constitute a valid assessment. However, clause 96 of the TAB provides that SARS has to give notice of an assessment to a taxpayer. Unlike the current s 106 of the Act (see discussion above) this clause does not provide for communication via electronic means. In addition, s 106 of the Act will be repealed. However, clause 98 does not indicate the way by which the type of notice, for example, $b$ ordinary post, registered mail or by electronic means, should be given. It is submitted that this is an important shortcoming in the TAB.

\section{TYPES OF ASSESSMENTS}

Currently, the Act provides for six kind of different assessments, namely

- an original assessment;

- an additional assessment (s 79)

- an estimated assessment ( $578(1)$ );

- an agreed assessment (s 78(2));

- a reduced assessment (S 79A); and

- an interim assessment s 66(4).

In the TAB these different types of assessments, with exception of an interim assessment, are retained. In addition provision is made for a new type of assessment to be issued, namely a jeopardy assessment. Under clause 94 SARS may in advance of the date on which a return is normally due, issue a jeopardy assessment if it is of the opinion that it has to do so to secure the collection of taxes. It is further specifically provided that in addition to the rights guaranteed under the Bill of Rights, a taxpayer may ask the Tax Court to review SARS decision to issue a 
jeopardy assessment on the basis that either the amount is excessive or that the collection of taxes is not at jeopardy.

Although jeopardy assessments are foreign to the South African tax landscape, they are wellknown internationally (Thuronyi Tax Law Design and Drafting (1996) 111). It is significant to note that the obligation to give notice of an assessment under clause 96 of TAB also applies to jeopardy assessments. This is contrary to international practice where the hall mark of a jeopardy assessment is that no notice that no notice of the assessment is to the taxpayer. The impression is thus gained that the purpose of a jeopardy assessment under South African law is to shorten the period within which tax is payable and not to do to away with the requirement to give notice of an assessment.

In light of the fact that the purpose of a jeopardy assessment is to ensure the payment of tax that is at jeopardy, the question may be asked what the difference between a jeopardy assessment and a preservation order (provided for in clause 163) is. Apart from the fact that a jeopardy assessment may be issued by SARS whereas a preservation order has to be issued by the High Court, the aim of both is to ensure the collection of taxes.

\section{WITHDRAWAL OF AN ASSESSMENT}

Under the current Act, once SARS issued an assessment it can only withdraw an assessment by issuing another assessment (CSARS v van Dijk 64 SATC 7). It is submitted that in the absence of a valid objection or one of the specific grounds stated in $S 79 B$, SARS only has three years to correct an assessment. The reason is that $s 79 \mathrm{~A}$ provides that SARS has to issue a reduced assessment within three years and $\mathrm{s} 81$ (5) provides that if a valid objection is not submitted within the prescribed period, an assessment becomes final and conclusive. The result is that even if an assessment is patently wrong, in circumstances where a taxpayer does not lodge an objection, SARS will have no authority to correct such an assessment after three years from the date of the assessment.

No doubt to address the above problem clause 98 of the TAB provides that SARS, notwithstanding that an objection was not lodged may issue withdrawn an assessment, which was issued -

a) to the wrong taxpayer;

b) for the incorrect tax period; or

c) due to an incorrect payment allocation

Unlike the current provisions of clause 98 (which are similar to the wording of the current $\mathrm{s} 79 \mathrm{~B}$ ) do not provide that SARS has withdrawn the assessment within three years. However, SARS still does not have a general authority to withdraw assessments as they may only do so on the grounds referred to above. In addition, clause 92 provides that if at any time an assessment does not reflect the correct application of a Tax Act to the prejudice of SARS or the fiscus (should presumably read the taxpayer), SARS must issue an additional assessment to correct the prejudice. As the wording of the section is extremely wide (i.e. correct the prejudice) and no time frame within which the additional assessment has to be issued is laid down, it is clear once the TAB is promulgated, SARS will have the general authority to correct mistakes without an objection being lodged by a taxpayer. In addition, it should be noted that SARS has no discretion whether to correct an incorrect assessment, but is obliged to do so. This is a welcoming change 
to the current law. In addition, clause 93 provides where SARS or a taxpayer in a tax return made an undisputed error SARS may issue a reduced tax return.

\section{GROUNDS FOR AN ASSESSMENT}

A welcoming feature in the TAB is that in the notice of an assessment SARS has to set out the grounds for the assessment (clause 96(2)). In other words, it has to give reasons for the assessment. This provision will help taxpayers in that they no longer have to request reasons before an objection against an assessment is lodged.

\section{PAYMENT OF TAX}

Clause 100 of TAB provides that an assessment becomes final inter alia if no objection was lodged or if an objection was withdrawn. It should be noted that similar to the current position, the obligation to pay tax does not first arise when an assessment becomes final. Under s 88 of Act, which will not be repealed by the TAB, it is made clear that a taxpayer has to pay tax notwithstanding that an objection was lodged or an appeal noted. This rule, which is commonly known as the "pay now argue later" rule is contained in the TAB in clause 164. Similar to the current rule, clause 164 allows SARS on request to suspend the payment of tax on certain specified grounds. In addition, it is provided in clause 164(3) that if SARS is requested to suspend payment of tax, if can for 5 business days not collect the tax the payment of which it is requested to suspend. The implication is that SARS has 5 business days to deal with the request for suspension of payment.

\section{CONCLUSION}

Most of the existing rules pertaining to assessments in the Act have been retained in the TAB. However, certain new rules, for example, the issuing of a jeopardy assessment as well as where SARS received a request for suspension of payment, collection of the amount is automatically suspended for five business days. Although it is far too early to judge the success of the TAB, the impression is gained that at least as e far as assessments are concerned, it succeeds in stricking a balance between the rights and obligations of SARS and taxpayers. 
ASSESSMENTS UNDER THE TAX ADMINISTRATION BILL 